\title{
Adjust your own oxygen mask before helping those around you: an autoethnography of participatory research
}

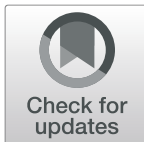

Abby M. Steketee ${ }^{1 *}\left(\mathbb{D}\right.$, Thomas G. Archibald ${ }^{2}$ and Samantha M. Harden ${ }^{1}$

\begin{abstract}
Background: There is a need to unpack the empirical, practical, and personal challenges within participatory approaches advocated to optimize implementation. The unpredictable, chaotic nature of participatory approaches complicates application of implementation theories, methods, and strategies which do not address researchers' situatedness within participatory processes. As an implementation scientist, addressing one's own situatedness through critical reflection is important to unearth how conscious and unconscious approaches, including ontological and epistemological underpinnings, influence the participatory context, process, and outcomes. Therefore, the aim of this exploratory work is to investigate the heretofore blind spot toward the lived experience of implementation researchers within the participatory process.

Methods: We developed an integrated research-practice partnership (IRPP) to inform the implementation of a gestational weight gain (GWG) control program. Within this IRPP, one investigator conducted a 12-month autoethnography. Data collection and triangulation included field notes, cultural artifacts, and systematic timeline tracking. Data analysis included ethnographic-theoretical dialogue and restorying to synthesize key events and epiphanies into a narrative.

Results: Analysis revealed the unpredicted evolution of the GWG program into a maternal health fair and three themes within the researchers' lived experience: (1) permeable work boundaries, (2) individual and collective blind spots toward the ontological and epistemological underpinnings of implementation paradigms, and (3) maladaptive behaviors seemingly reinforced by the research culture. These themes contributed to the chaos of implementation and to researchers' experience of inadequate recovery from cognitive, emotional, and practical demands. These themes also demonstrated the importance of contextual factors, subjectivity, and value-based judgments within implementation research.

(Continued on next page)
\end{abstract}

\footnotetext{
*Correspondence: abbyms@vt.edu

'Department of Human Nutrition, Foods, and Exercise, Virginia Tech, 1981

Kraft Drive, Room 1032, Blacksburg, VA 24060, USA

Full list of author information is available at the end of the article
}

(c) The Author(s). 2020 Open Access This article is licensed under a Creative Commons Attribution 4.0 International License, which permits use, sharing, adaptation, distribution and reproduction in any medium or format, as long as you give appropriate credit to the original author(s) and the source, provide a link to the Creative Commons licence, and indicate if changes were made. The images or other third party material in this article are included in the article's Creative Commons licence, unless indicated otherwise in a credit line to the material. If material is not included in the article's Creative Commons licence and your intended use is not permitted by statutory regulation or exceeds the permitted use, you will need to obtain permission directly from the copyright holder. To view a copy of this licence, visit http://creativecommons.org/licenses/by/4.0/ The Creative Commons Public Domain Dedication waiver (http://creativecommons.org/publicdomain/zero/1.0/) applies to the data made available in this article, unless otherwise stated in a credit line to the data. 
(Continued from previous page)

Conclusion: Building on extant qualitative research guidelines, we suggest that researchers anchor their approach to implementation in reflexivity, intentionally and iteratively reflecting on their own situatedness. Through this autoethnography, we have elucidated several strategies based on critical reflection including examining philosophical underpinnings of research, adopting restorative practices that align with one's values, and embracing personal presence as a foundation of scientific productivity. Within the predominant (post-) positivism paradigms, autoethnography may be criticized as unscientifically subjective or self-indulgent. However, this work demonstrates that autoethnography is a vehicle for third-person observation and first-person critical reflection that is transformative in understanding and optimizing implementation contexts, processes, and outcomes.

Keywords: Implementation, Novel methods, Epistemology, Knowledge translation, Context, Engagement, Qualitative research, Anthropology

\section{Contributions to the literature}

- This work suggests that theory-based autoethnography (i.e., personal narrative) is a thought-provoking, action-inspiring method for capturing implementation processes and outcomes, particularly within participatory research.

- In recognizing how their own values, beliefs, and behaviors influenced the project at hand, researchers identified several strategies for thriving in the chaos of implementation.

- These strategies emphasize reflection, well-being, and presence as tools toward personal, professional, and scientific clarity.

\section{Background}

In translating research findings to real-world benefit, participatory research [1-4] purportedly embodies the spirit of a quote often attributed to cultural anthropologist Margaret Mead: "Never doubt that a small group of thoughtful, committed citizens can change the world: indeed, it is the only thing that ever has" [5] (p. 111). As a vehicle for change, participatory research is characterized by active collaboration between researchers and diverse stakeholders [1]. This collaboration is intended to empower stakeholders-specifically those who are underrepresented in research decision-making-to shape all aspects of research, ultimately optimizing how a program or policy works within stakeholders' unique lives and communities $[4,6]$. Overall, participatory research holds promise as the backbone of pragmatic [7] implementation [8] to promote feasible, user-friendly applications of research findings to the daily lives of community members.

However, as participatory research has become more common, experts have uncovered a "dark side" to this collaborative model with practical, personal, and professional costs to researchers, as well as costs to stakeholders, the research itself, and research as a profession
[9]. Ample evidence suggests that participatory research poses people-oriented, emotionally charged challenges plus complicated logistics and scheduling barriers in constant flux [10-14]. Exemplifying the emotional dimension of these challenges, researchers in recent focus groups described pursuing dissemination and implementation (D\&I) science as "intimidating" and "career suicide" [15]. Furthermore, within participatory processes, researchers may have to navigate conflict and tension related to organizational change and feedback loops, particularly when there are power differentials between stakeholders (e.g., physician and patient) [10]. The unpredictable nuances of working within complex human environments can be chaotic [10], challenging the usability of current implementation theories, methods, and strategies [16, 17] that do not specifically acknowledge researchers' roles or intrapersonal resources to initiate and maintain participatory processes [18].

In addition, the uncontrollable, value-laden nature of a participatory approach $[19,20]$ seems incommensurable $[21,22]$ with positivist or post-positivist paradigms reflected in mechanistic implementation advancements such as quantification of discrete implementation activities [23] and calls for deductive qualitative research [24]. In general, (post-) positivist paradigms emphasize systematic a priori hypothesis testing, experimental control, elimination of bias, generalizable predictions, and research quality determined by conventional internal and external validity aimed at explanation. In contrast, constructivist (sometimes called interpretive) paradigms emphasize the subjective nature of knowledge, naturalistic inquiry with participant voice, reflexivity, iterative theorizing, and research quality determined by trustworthiness aimed at understanding meaning $[19,25,26]$. For additional description of scientific paradigms, see Table 1 in Greenhalgh et al. [26] or Table 6.2 in Guba and Lincoln [19].

Indicating an opportunity to look beyond (post-) positivist paradigms, emergent research suggests that 


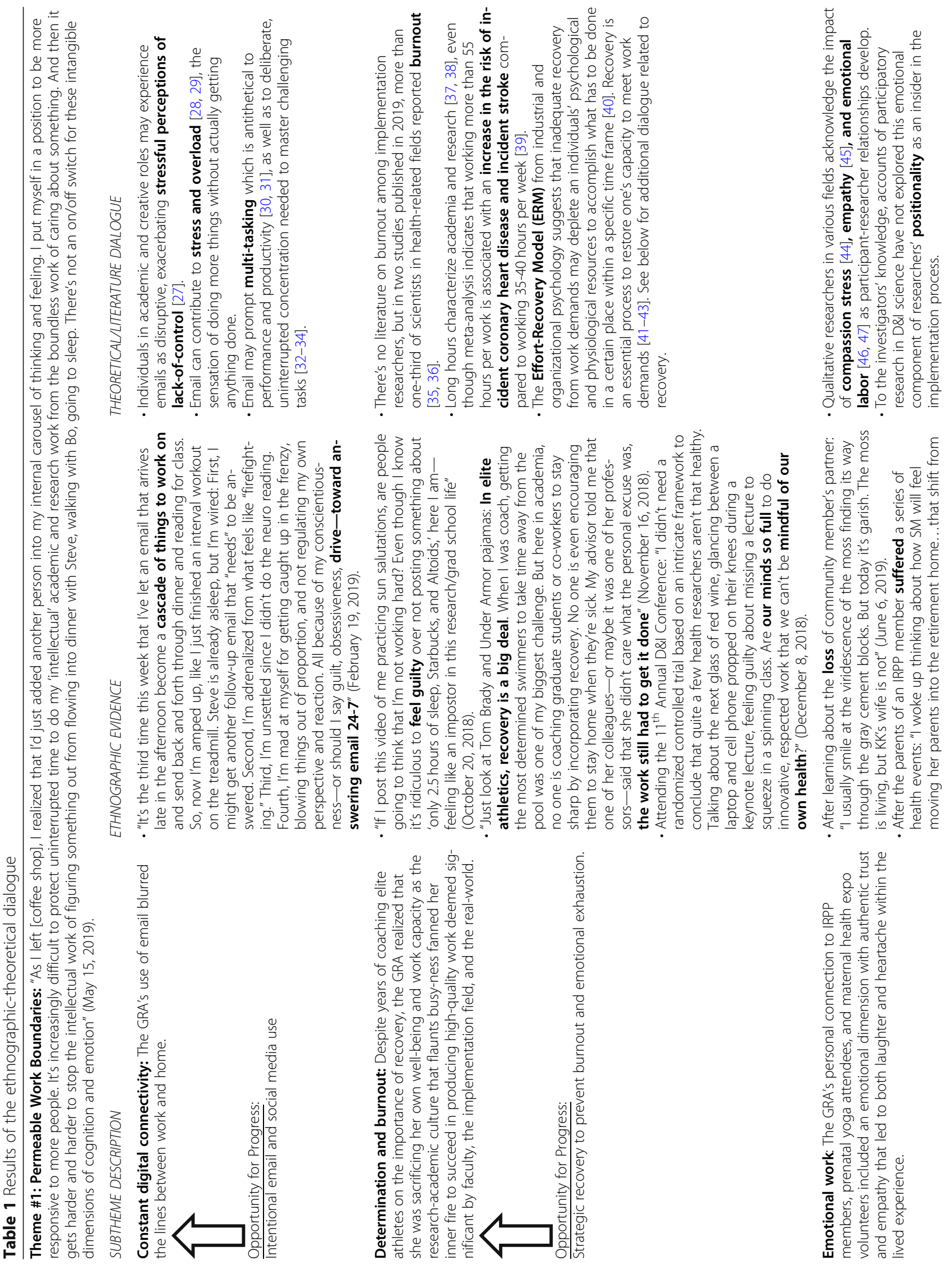




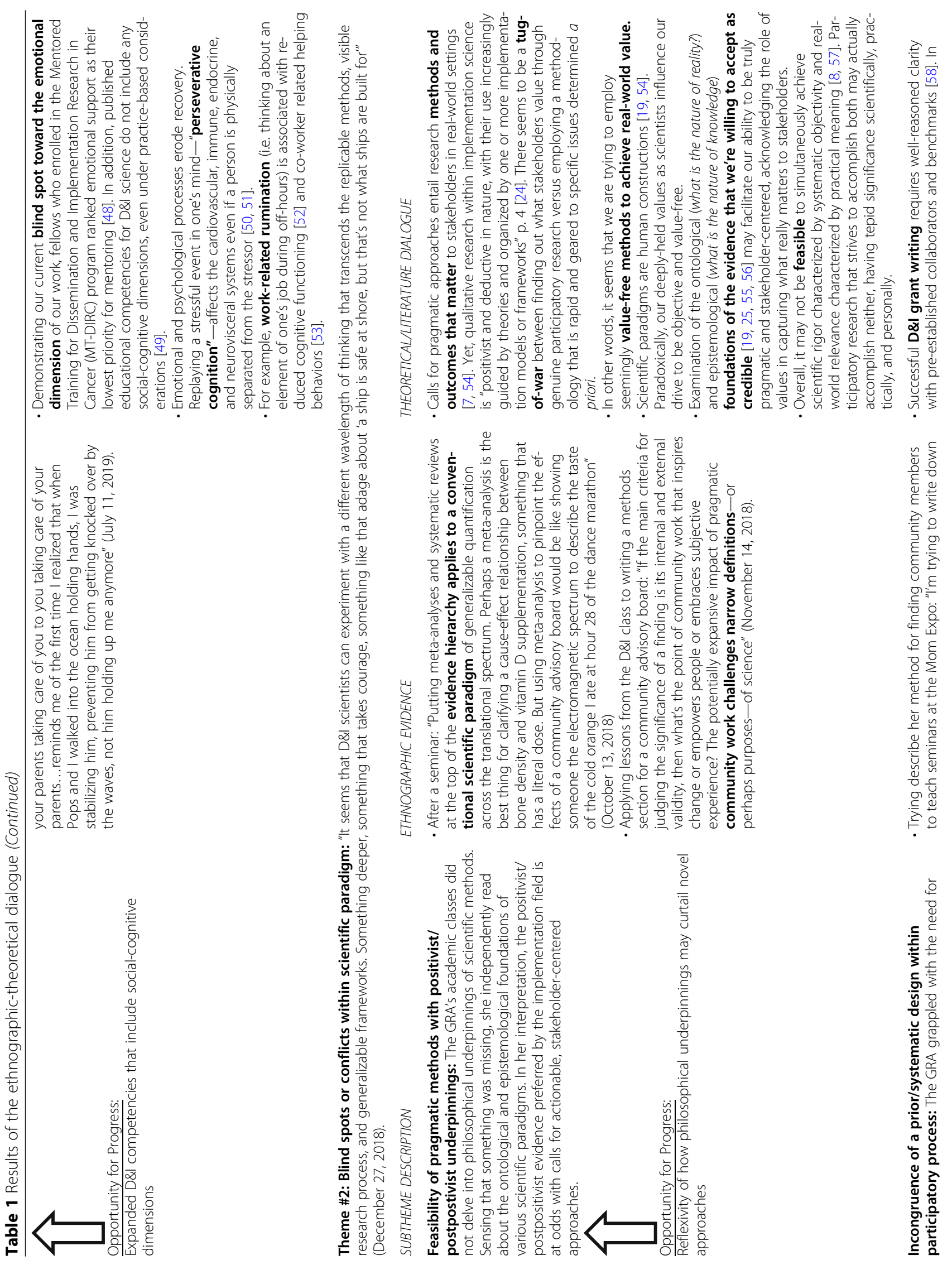




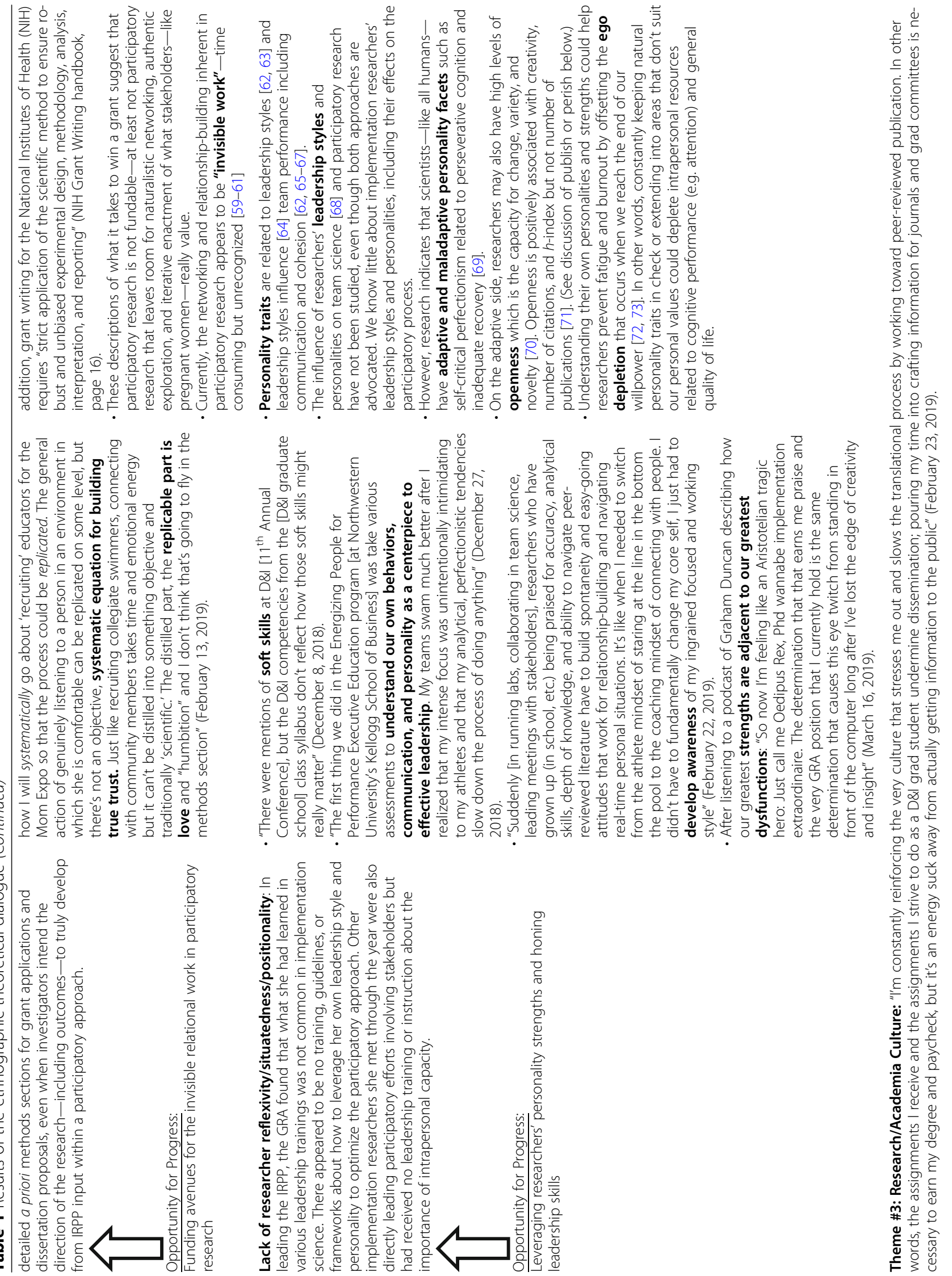




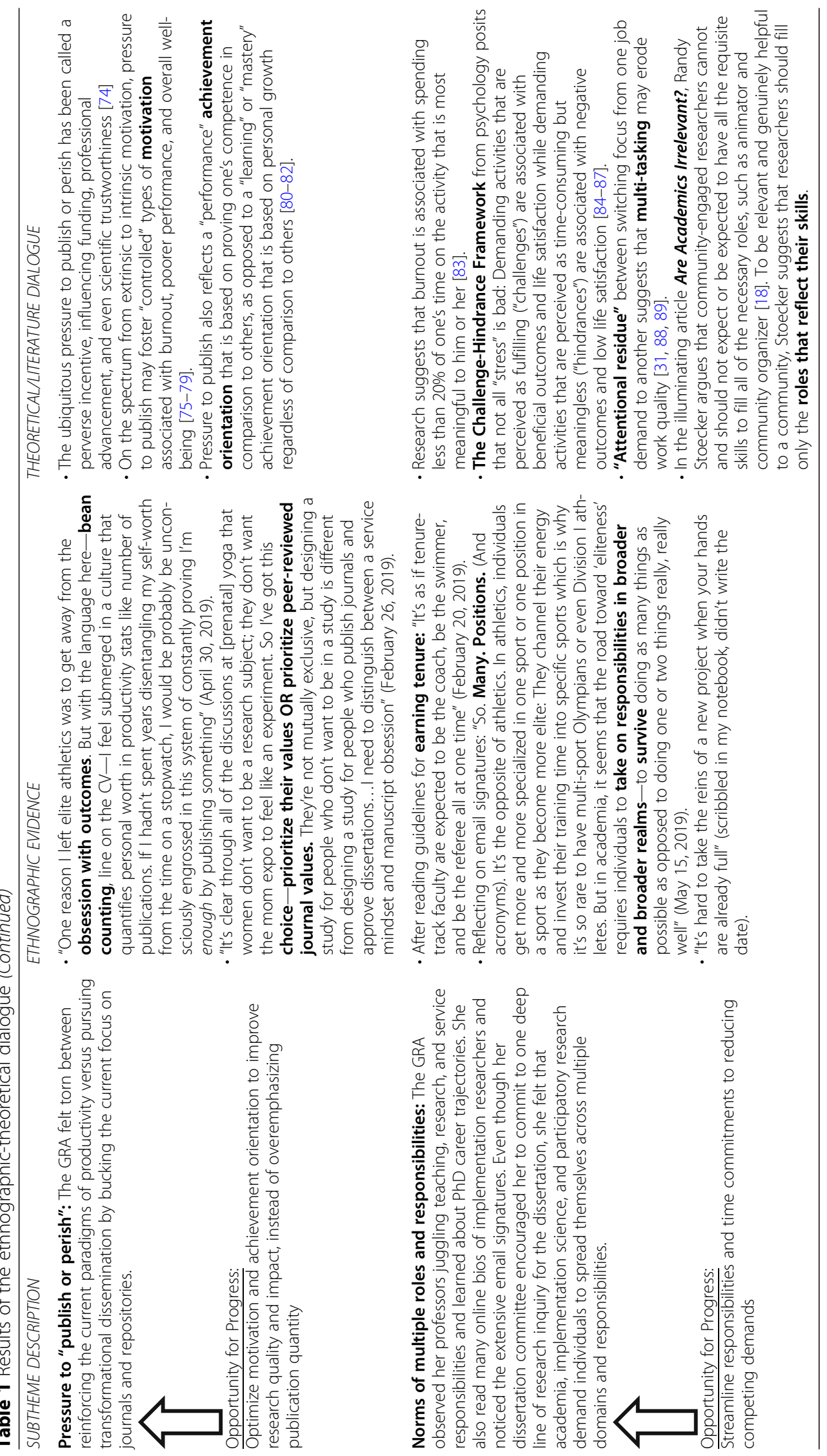


mundane, hidden tasks fuel the implementation process [90]. However, there has been a blind spot to the effect of researchers' "situatedness," including intrapersonal resources, values, and ideologies [91, 92], within this hidden dimension of implementation. Moreover, current literature does not include day-to-day, concrete strategies that researchers can use to acknowledge and leverage their situatedness and, therefore, optimally cope with professional and personal challenges within participatory approaches [9]. There is a need to critically investigate the ground-level work within the lived experience of participatory research [11] in order to unpack the black box of implementation [93], including how our own conscious or unconscious situatedness as researchers influences the implementation process.

Therefore, the aim of this research was to explore and analyze what happened in 1 year of a participatory research project dedicated to maternal well-being. For this exploration, researchers employed a novel autoethnographic approach. Autoethnography appears to be a relatively untapped methodology in implementation science [10] and offers a fluid, qualitative approach to capturing the nuanced, inter- and intra-personal micro-processes of how a participatory effort unfolds within an unpredictable real-world, community context [24, 25, 94]. We argue that autoethnography is an appropriate method to investigate current implementation blind spots such as researchers' situatedness. In combining first-person and third-person perspectives, autoethnography may capture the impact of blind spots and situatedness on all aspects of research from stakeholder interactions to data analysis and interpretation

In exploring nuanced processes, autoethnography combines two central components of science-observation and critical thinking [93, 95]. What autoethnography lacks in conventional control and a priori systemization is made up for by ongoing, interdisciplinary, theoretical dialogue, and critical reflection. Critical reflection [96-98] has not been explicitly explored as a method of implementation inquiry above and beyond the standard integration of reflexivity within qualitative studies. However, in fields such as education and cognitive science, critical reflection is practiced and studied as a process "that allows us a rigorous approach to the scientific work...because it enhances the capability of the mind to go in depth in its life" [98] (p. 7). Intentionally embracing such a subjective method within implementation science poses various limitations, particularly within dominant (post-) positivist paradigms. Therefore, the discussion section includes an assessment of credibility, transferability, dependability, and confirmability as measures of trustworthiness $[24,99,100]$.

This work is significant for three primary reasons. First, it dives beneath the current mechanistic understanding of participatory research by attempting to capture and narrate the complete story and lived experience of implementation, including cognitive-socialemotional phenomena that may elude quantitative methods and current paradigms. Second, the autoethnographic approach may be replicated in other implementation investigations as a rigorous and meaningful method for studying contexts, processes, and outcomes, as depicted in Fig. 1. Third, this work informs actionable strategies for personal stability and empirical depth within the chaos of implementation.

\section{Methods}

An integrated research-practice partnership (IRPP) is a strategic collaboration of stakeholders and researchers to plan, implement, evaluate, and sustain local evidencebased programs [103-106]. In 2009, when the primary investigator (PI, the senior author) was a graduate research assistant learning a specific IRPP approach, she established an IRPP in Southwest Virginia (see Fig. 1) to support the development, delivery, and evaluation of a gestational weight gain (GWG) control program [107]. However, due to high turnover among IRPP members and the departure of the PI who accepted an international postdoctoral position, progress on implementing the GWG control intervention came to a halt. This reflects the common phenomenon of "parachute" research $[108,109]$ in which researchers disappear from a community setting when empirical work is complete or academic demands arise.

From 2014 to 2018, after completing the postdoctoral fellowship, the PI re-established her community connections and conducted foundational collaborative work on preconception weight management. In 2018, the PI recommitted to prenatal health interventions, pursuing her passion for disseminating evidence-based health information and self-compassion practices to individuals within the gestational period. The graduate research assistant (GRA) whom she hired to manage and evaluate a new IRPP is the first author of this manuscript and conducted autoethnography of her experience implementing the IRPP from July 2018 to July 2019.

In conducting autoethnography, the GRA served as a participant observer [94, 110] simultaneously leading and studying the IRPP. The GRA recorded real-time observations of meetings, interactions, and events as "jottings" which she subsequently expanded into field notes [111]. The GRA wrote field notes for a minimum of 10 min after IRPP-related meetings and events. The GRA also collected cultural artifacts such as meeting agenda, meeting minutes, flyers, and emails $[24,93,111]$ and systematically tracked attendance at meetings, start/end times of meetings, adherence to meeting agenda, adherence to communication protocols, and a detailed 


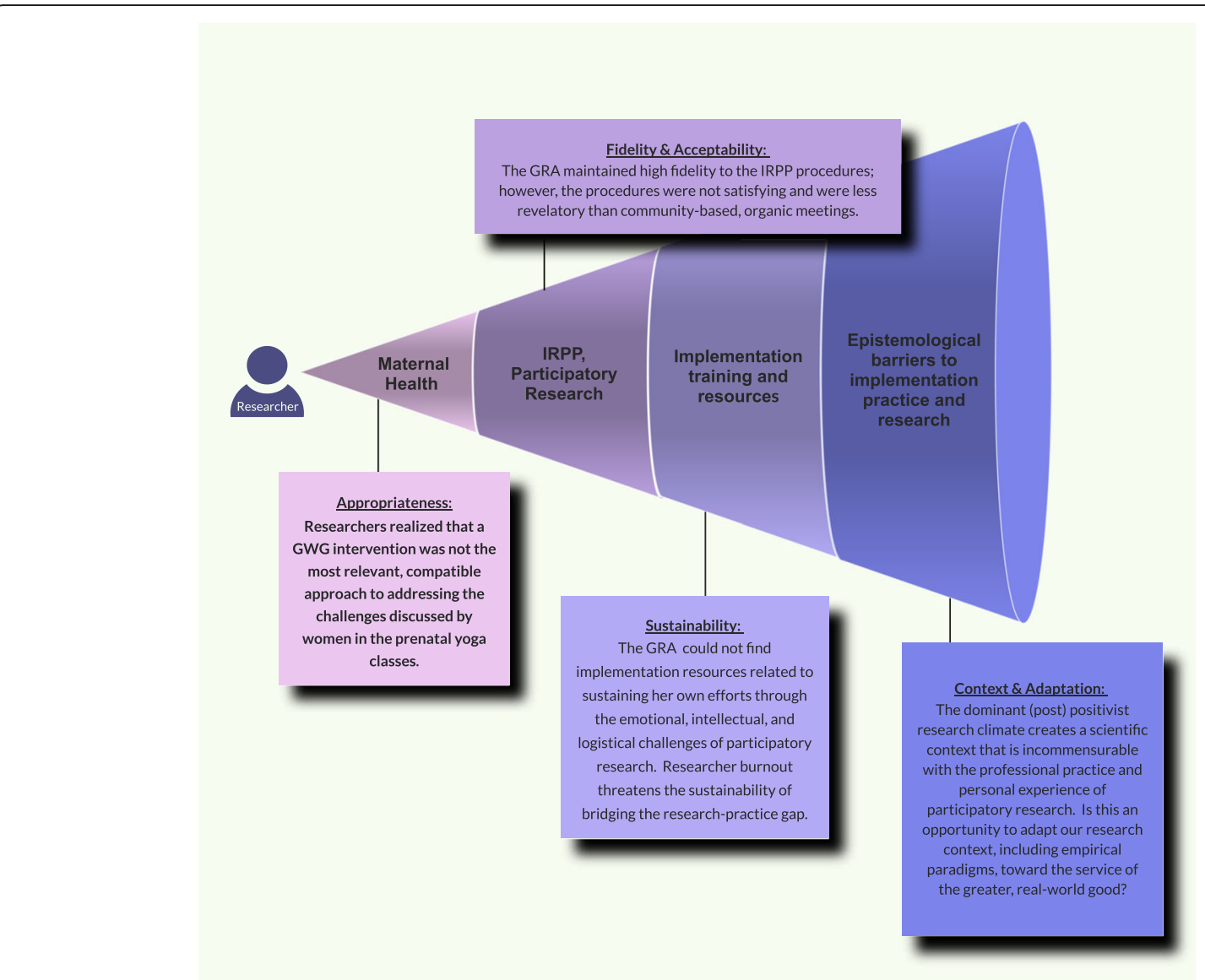

Fig. 1 Autoethnography: informing implementation processes and capturing implementation outcomes [101, 102]

timeline to measure temporality of implementation efforts and strategies [23].

To capture her own cognitive-social-emotional experience within the work, the GRA wrote general field notes for at least $1 \mathrm{~h}$ per week as a process of critical reflection and self-inquiry in which she "play[ed] at the same time the role of subject who reflects and object who is reflected" [98] (p. 1). True to theoretically informed ethnography [110], she iteratively integrated evidence-based concepts and classical theories from other fields [112] so that the fieldnotes were simultaneously data collection and data analysis. This ongoing interdisciplinary [113], "ethnographic-theoretical dialog" [110] is rooted in qualitative research paradigms that emphasize the valueladen, fluid nature of reality (ontology), and knowledge (epistemology) [19, 20, 25].

To capture her own cognitive-social-emotional experience within the work, the GRA wrote general field notes for at least $1 \mathrm{~h}$ per week as a process of critical reflection and self-inquiry in which she "play[ed] at the same time the role of subject who reflects and object who is reflected" [99] (p. 1). True to theoretically informed ethnography [110], she iteratively integrated evidence-based concepts and classical theories from other fields [112] so that the fieldnotes were simultaneously data collection and data analysis. This ongoing interdisciplinary [113], "ethnographic-theoretical dialog" [110] is rooted in qualitative research paradigms that emphasize the valueladen, fluid nature of reality (ontology), and knowledge (epistemology) [19, 20, 25].

To organize and further analyze the ethnographictheoretical dialog, investigators (i.e., the PI and GRA) used a chronological approach called restorying [94] to identify epiphanies or key events within the data and synthesize them into a narrative with the five elements of literature-characters, setting, conflict, plot/action, and resolution. From these elements, investigators generated, interpreted, and presented themes and practical implications of the narrative.

The investigators obtained consent from all IRPP members and protocol approval from the university Institutional Review Board. The GRA's approach to this work reflects her Master's of Public Health, academic training in journalism and human development, 15 years of leadership experience as a collegiate swim coach, and ongoing study of yoga. An experienced yoga teacher and 
practitioner, the PI's approach to this work incorporates her empirical and practical expertise in pragmatic methods, group dynamics, community-based physical activity, and implementation science. Both investigators were full, active members of the IRPP and neither investigator is a parent; therefore, the investigators simultaneously managed "insider" and "outsider" roles [46, 109, 114] within this participatory project aimed at maternal well-being.

\section{Results}

The presentation of autoethnographic results is a result in and of itself and evidence of the difficulty operationalizing novel methods within current scientific norms such as the common format of peer-reviewed journals. In this project, separating data and interpretation may dilute the reflective, iterative nature of ethnographictheoretical dialogue. Therefore, investigators suggest that readers iteratively refer to Table 1 throughout the "Results" and "Discussion" sections to experience the visceral-intellectual rhythm of autoethnography and critical reflection. In Table 1, investigators present results of the ethnographic-theoretical dialogue, and in the subsections below, investigators report the results of restorying, including plot, setting, characters, conflicts, themes, and resolution.

\section{Restorying: plot and setting}

The IRPP's narrative is set in Southwest Virginia where the connection between a public land-grant university and local health care system developed over more than a decade. As depicted in Fig. 2, the IRPP's "plot" within this setting dramatically shifted from July 2018 to July 2019. In July 2018, the IRPP convened to plan a randomized controlled study (RCT) of a GWG control program. Investigators aimed for the study to be a systematic step in "scaling out" [115] the program by delivering it through videoconference. To adapt the program, the GRA intended to develop a community advisory board as an additional arm of the IRPP. As the investigators worked with local women to film prenatal physical activity videos, the plans for a community

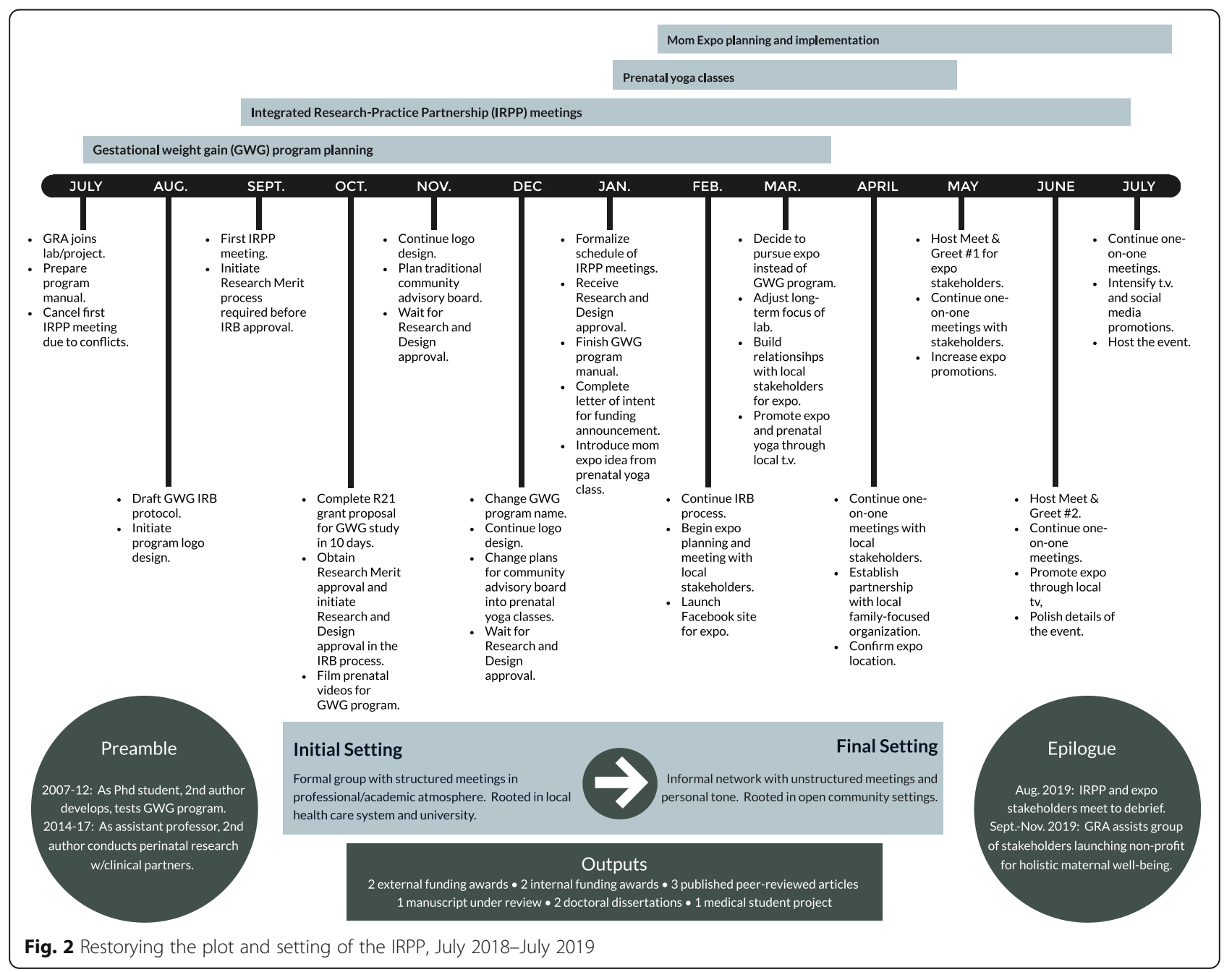




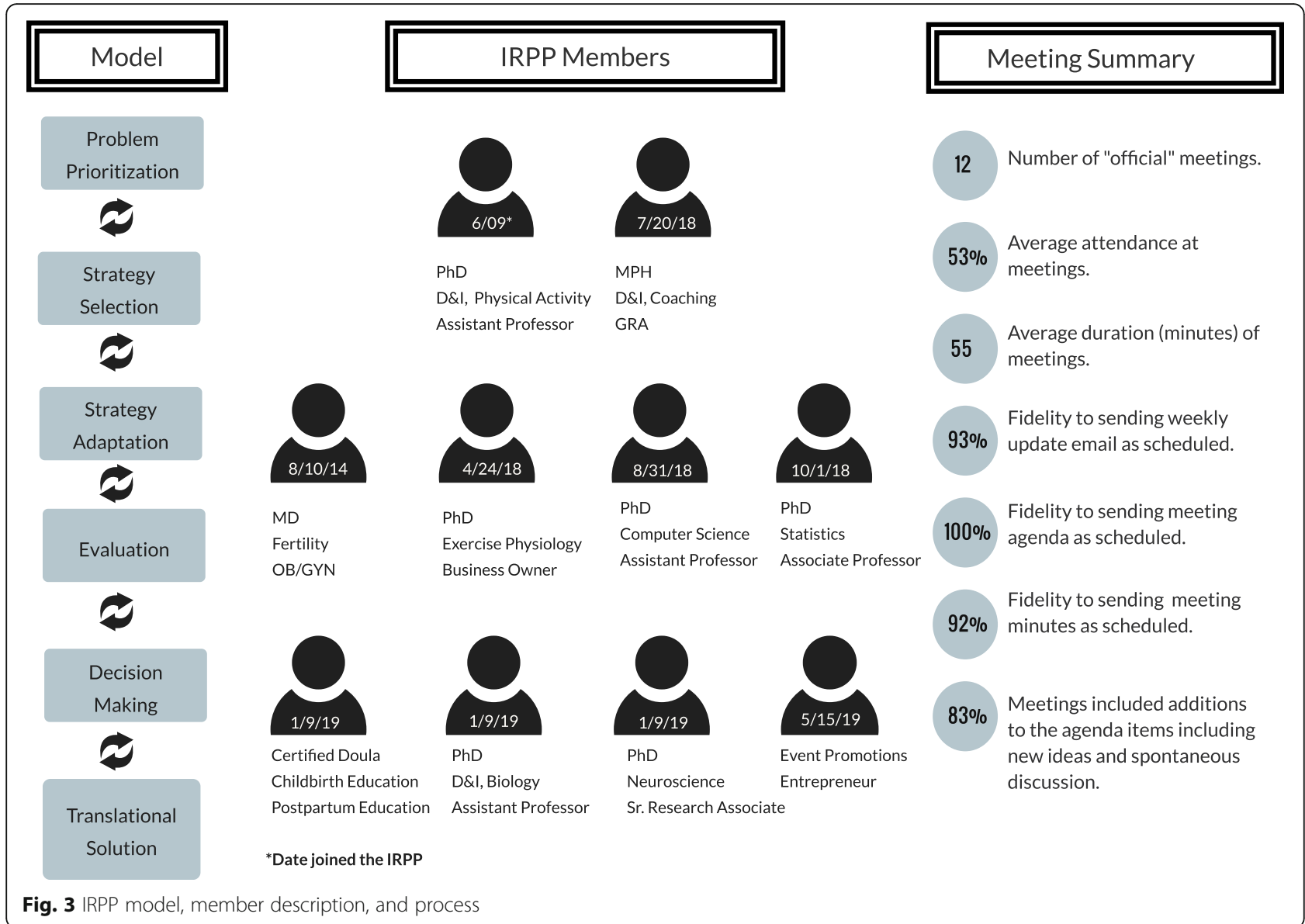

advisory board morphed into free prenatal yoga classes. Attendees of the prenatal yoga classes suggested the idea of a 1-day, family-friendly event for local women. This idea developed into the planning, implementation, and pragmatic evaluation of a maternal health fair to empower, educate, and connect local mothers in July 2019. The event featured 23 local educators including a lawyer, physical therapist, music therapist, and neuroscientist, who presented interactive workshops including "Self-Advocacy at Home, Work, and Your Doctor's Office," "Pelvic Floor Exercises for Pregnancy and Postpartum," "Music for Labor Through the Early Years," and "Mommy Mind" (manuscript under review). See Fig. 3 for the structure and composition of the IRPP in the year leading to the maternal health fair.

Within data collection and analysis, it was apparent that understanding the IRPP's "plot" required looking beyond the 12-month autoethnography: "The IRPP isn't in a petri dish. [The PI] has been working on [the GWG program] since she was a graduate student and there's already discussion about how this is just the first Mom Expo [the maternal health fair], just one step toward better connections for pregnant and postpartum women.
When I get caught up in the 12-month time frame of the protocol, I forget that the IRPP actually exists on a continuum of time and life with all sorts of inputs and outputs. It's not like a carefully prepared sterile slide under a microscope" (field notes, June 6, 2019). In other words, what led to this IRPP and what stems from it extends before and after the empirical, researcherestablished boundaries of a project (see preamble and epilogue in Fig. 2).

Within this unbounded "setting," seemingly mundane interpersonal interactions rippled into longterm effects. For example, the GRA established a connection with a local community member who attended a single prenatal yoga class in March 2018. That community member provided an introduction to a leader of an existent local non-profit organization who agreed to host the first event of the new non-profit organization that developed from the maternal health fair that originated in the yoga classes. In other words, a single interpersonal relationship that developed within a prenatal yoga class that was not part of the initial IRPP plan contributed to the significant, unpredicted long-term community 
benefit of a non-profit organization for holistic maternal well-being. Likewise, other interpersonal connections the GRA developed within the community led to promotional spots on local television stations and reduced financial costs for hosting the maternal health fair. "This whole thing is like the butterfly effect: I don't know how or when I meet someone will lead to something else later down the road" (field notes, July 28, 2019). The butterfly effect, first demonstrated by Edward Lorenz in mathematical models of weather predictions, describes how seemingly inconsequential events eventually contribute to significant outcomes in a later state [116], as in the flapping of a butterfly's wings in Brazil causing a tornado in Texas [117]. The butterfly effect provides a metaphor for the dynamic, unpredicted effects of spending time with community members within informal settings that belie conventional scientific protocol.

Based on the GRA's initial D\&I science training in a graduate course, she expected "what happens in an IRPP" to be a slow but steady, systematic but iterative flow. "The language about implementation frameworks, theories, and processes from D\&I class implies a slow but continuous spread: diffusion [italics included] of innovations, 17 years to move through the traditional pipeline from basic science to uptake in the real world, iterative and ongoing balance of fidelity and adaptation. It sounds very Darwinian - gradual evolution, survival of the fittest. Even the language of a diffusion 'champion' conjures up an image of the 'fittest"' (field notes, December 9,2019$)$. However, in terms of metaphors from natural science, the full IRPP story resembles punctuated equilibrium (PE) [118]. PE is a model of evolution that describes change patterns in nature as occurring through periods of relative stability suddenly punctuated by rapid adaptation [118]. Social science researchers have recently used this evolutionary model to describe the delayed benefits of coaching when a certain event triggers an epiphany that catalyzes an individual to suddenly enact what he or she previously learned in coaching [119]. Likewise, evaluation scientists have highlighted "evolutionary epistemology" and posited that the natural selection of what knowledge survives and spreads in the realworld is not a "foreordained" process but takes place in "fits and starts" [120] (p. 4). These fits and start are evident in the full story of the IRPP which spans chunks of "latent" time punctuated by blocks of intense activity in 2008-2009, 2011, 2014, and 2018-2019. Even within 2018-2019, there was a distinct shift in pace (i.e., a punctuation) when the prenatal yoga classes catalyzed action toward the maternal health fair. The catalysts for the action were not the mechanistic operations of the IRPP, but the characters and conflicts within the story.
Restorying: characters, conflicts, and themes

On the surface, the PE pattern of IRPP-related work was contingent upon investigators' situatedness as graduate students: The highest intensity blocks occurred during 2008-2009 when the PI initiated the GWG program and community partnerships as a graduate student, and during 2018-2019 when the GRA managed the IRPP and founded the health fair. Graduate education resources such as predoctoral fellowships, protected time, and supervision from experienced advisors enabled intense empirical and practical activity: The investigators' "situatedness" [29] as graduate students set the stage for generating ideas, completing time-intensive research, and establishing extensive personal networks through a participatory approach.

Beneath the concrete academic resources, the investigators' lived experience demonstrated their situatedness as human beings [109] with ever-present emotions, deep values, limited time, and finite energy making them vulnerable to strain [121] from work demands. For example, the GRA experienced emotional exhaustion and ego depletion [72, 73] stemming from a complicated web of her own associative thinking [71], maladaptive perfectionism $[69,122]$, and perseverative cognition [50, 51] that was exacerbated by a publish or perish research culture $[74,123]$ rooted in extrinsic motivation $[75,76]$ and performance achievement orientation [124]: "All year I've felt like I'm on a wild-goose chase or playing some Alice-in-Wonderland version of dominoes, balancing what a dissertation committee values as science with what prenatal yoga women value as life, all while keeping up a can-do attitude and A+ quality amidst the constant topple of...'let's change the name for [the GWG program]'...'actually, let's not do the [GWG program]'...'you have to have a research question"' (field notes, March 25, 2019). The autoethnographic process itself helped the GRA recognize how her own cognitive patterns contributed to her exhaustion, and subsequently, she was able to reshape maladaptive rumination and over-analysis into insightful reflection $[125,126]$.

Critical reflection within this research design illuminated dissonance between the investigators' professional, conventionally scientific roles and their person-centered participatory roles. The difficult decision to pivot away from an RCT epitomized this conflict: In implementing a pragmatic maternal health fair instead of an intervention RCT, the investigators intentionally chose to prioritize participatory input over traditional a priori empirical processes: “I can't truly empower people in the spirit of participatory research if the only way to achieve 'rigor' is to march steadily forward on a pre-fixed, 'systematic' path based on a priori research questions, not on the destination women really seek" (field notes, 
March 13, 2019). In addition, this shift manifested investigators' epiphany that GWG was not local mothers' central need: "...we get caught up in creating band aids, not treating wounds. Bandaids are kind of like packageable, tidy interventions for narrow health outcomes, like GWG, that are important but not the real source of suffering, not the central thing that heals the core issue or fuels all-around well-being...To achieve something sustainable that people want to maintain with fidelity, we have to get at the underlying root issue and what really matters to people, even if it's hard to measure." (field notes, February 24, 2019).

With this epiphany, the GRA's work expanded from leading structured IRPP meetings to spending one-onone time with stakeholders out in the community in non-academic, non-clinical settings such as coffee shops and libraries. From July to March, the IRPP had inched toward launching the RCT as investigators grappled with organizational red tape and convoluted procedures within the clinical system: "Busyness gets in the way of business. There's tons of horizontal movement-as in digital horizontal movement as emailsemailsemails gobble up the day-but no vertical progress toward the mountain peak" (field notes, October 14, 2019). In contrast, progress toward the health fair was rapid, including partnerships with an existing family-oriented organization and local library, as well as commitments from nearly 40 individuals to volunteer their service, expertise, and energy at the health fair. "I get so much more input from one-on-one get-togethers out in the community then when I run IRPP meetings with agenda and minutes and action items. The IRPP meetings are systematic and trackable; but for all the organization (i.e. replicable processes worth publishing in a journal), they don't seem nearly as authentic as the one-on-one meetings with women out in their community...where I'm making traction, where I feel like I'm gaining insight into community dynamics, where relationship-building doesn't feel like a mercenary research task" (field notes, April 12, 2019).

In living out these epiphanies and conflicts, investigators identified three themes: (1) permeable work boundaries [127], (2) individual and collective blind spots toward the ontological and epistemological underpinnings of implementation paradigms, and (3) maladaptive behaviors seemingly reinforced by the research culture. See Fig. 4 for a diagram of the themes and Table 1 for subthemes, ethnographic evidence, theoretical/literature dialogue, and untapped opportunities for progress.

One lens for interpreting these intertwined themes is structuration theory [128] which "refers to the idea that rules, policies, and structures are only made 'valid' when individuals follow them and make decisions based upon them" (p. 59) [25]. In other words, the GRA's own behaviors-her individual "micro-practices"-reinforced the publish or perish culture and (post-) positivist paradigms that may hamper participatory research and wellbeing. For example, in the first 6 months of the project, the GRA's drive for achievement reinforced her situatedness in a culture of workism [127]: "I was tossing deep thinking out the window so that I could keep driving forward as fast as possible...my ambition to be more 'productive' devoured my responsibility for self-care" (field notes, December 27, 2018). But as the IRPP work turned to relationship building in the second 6 months, the GRA found some traction by distinguishing between presence and productivity: "I cannot control all of the variables that go into scientific productivity, but I can control where and how I choose to focus my energy... the depth and deliberateness of my presence in each and every conversation even if I cannot control an editor's or committee member's reaction to a paper I write" (field notes, March 21, 2018). This distinction did not lead to a mindful panacea of constant ease. Instead, it has led to unease knowing that challenging the prevalent implementation structure may lead to conflict and rejection within the field.

The field has made significant advancements in developing toolkits to clarify empirical outcomes of implementation [101], establish skill-based mentoring [48], and promote qualitative methods that capture nuanced micro-processes [24]. Furthermore, at the 2018 and 2019 Annual Conferences of the Science of Dissemination and Implementation in Health, there were calls to acquire "soft" skills. However, we have yet to appropriately operationalize these calls and advancements by determining what roles an implementation scientist should or could realistically play within participatory research [18] based on their unique skills, training, personality, values, and time-in other words, based on their situatedness and finite human capacity [73]. The lack of awareness or reticence to recognize personal situatedness and limits of human capacity [73] may be a result of traditional scientific paradigms that dominate health research: The structure of grant writing [58], system of tenure (cultural artifact, university tenure guidelines), emphasis on outcomes [102], and alignment with conventional benchmarks of rigor such as objectivity and internal/external validity $[7,129,130]$ indicate dominance of (post-) positivism [19, 20, 25]. Likewise, the general style of reporting results in peer-reviewed journals reflects a paradigm of value-free objectivity. Researchers generally write methods sections in a passive voice (e.g., "data was collected..."); avoid the subjective pronouns $I$, $w e$, and you; and describe procedures that are measurable and replicable. Minimizing attention to the inherent role of their own five senses and cognition, researchers often un-situate themselves as an indication of unbiased 


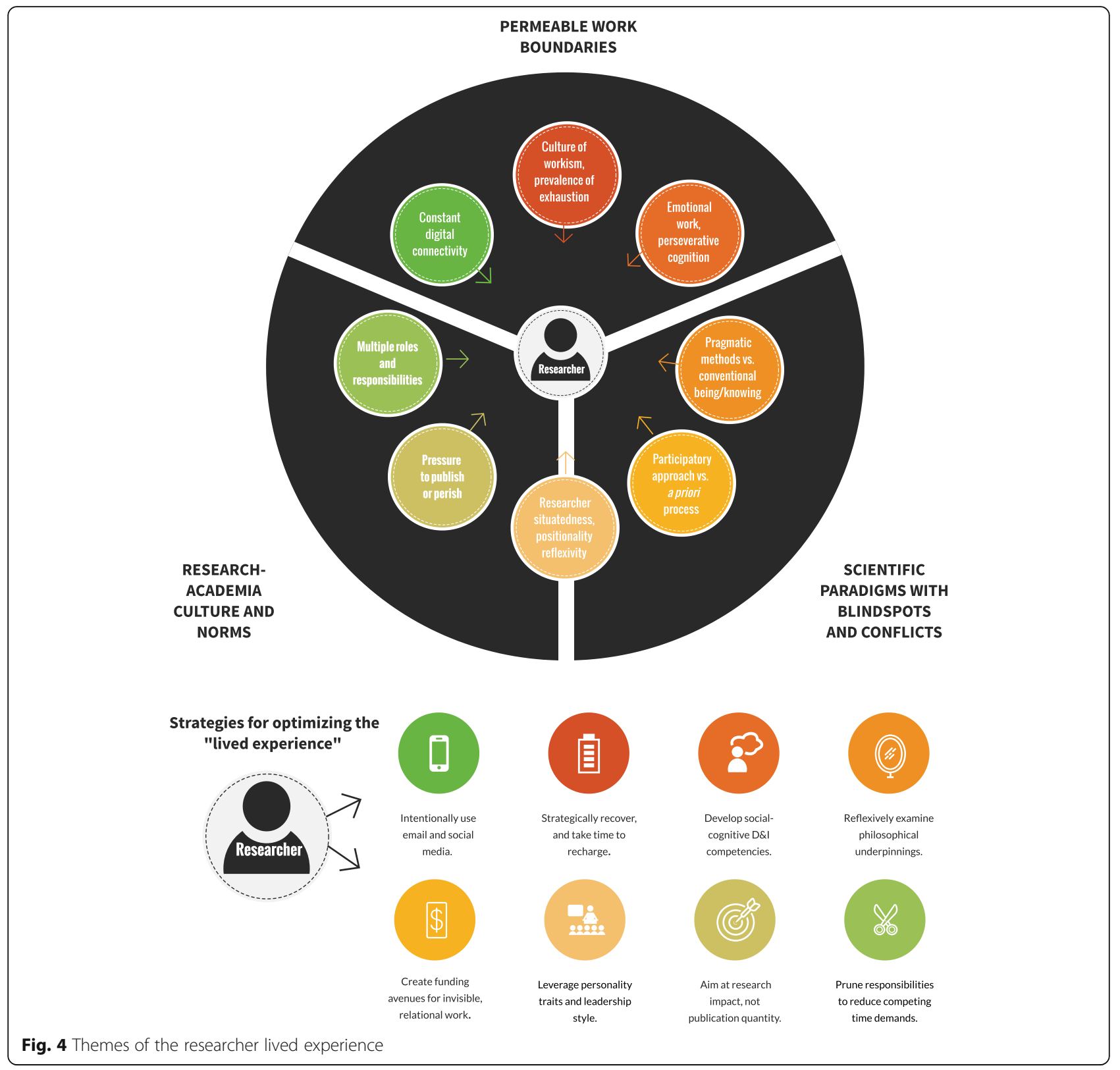

validity and reliability. This paradigm of projecting machine-like expertise seems incommensurable with both reflective practice $[96,97]$ and participatory research which hinges on researchers' moral drive to make a difference in the real-world and their ability to build trust with stakeholders [131]. Building trust is a human-not scientific-venture, and this ethnographic-theoretical dialogue suggests that researchers' humanness-for example, being "too tired to inspire" [64] —is a critical component of the black box of implementation. Furthermore, researchers' deep philosophical views and scientific training may limit their perspective on novel ways to open that black box. For example, authors of a recent implementation autoethnography observed an "underlying tension between the production and use of generalizable knowledge" caused by conflicting scientific paradigms [10] (p. 6). This paper avoids that trap by elucidating strategies to uncover paradigm conflicts that reduce the usability of findings (see the "Conclusion" section).

Fields such as education and mindfulness have embraced debates on the ontological and epistemological foundations of research and practice [97, 98, 132-134], and the emerging idea of value-based medicine $[135,136]$ emphasizes philosophical underpinnings and patient empowerment [20]. However, implementation dialogue focuses on the methodological level of what constitutes credible evidence, not philosophical viewpoints of reality and knowledge [55]. The lack of clarity on these 
ontological and epistemological levels may contribute to the chaos [17] and lexicological quagmire [8, 112, 113, 137] often described within implementation science. A firm footing in the field's beliefs about science may provide a foundation to stabilize at least some of the chaos: "Time and time again, I've seen that the swimmers who consistently win aren't always the ones with the most efficient stroke or highest V02 max-it's often the ones who had the strongest why, the clearest perspective of what a race meant, a purpose beyond the numbers on the record board..." (field note, February 2, 2019). Paradoxically, the coaches and athletes who win the most are often the ones who anchor their focus on a purpose beyond winning, beyond tangible outcomes measured by a stopwatch or counted in a win-loss record [138, 139]. In contrast, the GRA observed an overemphasis on outcomes over process and methods over philosophy within the IRPP, implementation literature, and academic research environment. It was through the process of autoethnography that the GRA unearthed her own ontological and epistemological assumptions; she experienced the effectiveness of reflective practice to clarify her own philosophy as a stabilizing point within the messiness of implementation.

\section{Restorying: resolution}

The resolution of the 12-month study indicates empirical, practical, personal, and philosophical evolution. On the empirical level, the GWG control intervention evaluated through RCT evolved into a health fair evaluated through the pragmatic application of the RE-AIM framework [140] (manuscript under review). On the practical level, the GRA's work evolved from leading an IRPP in a systematic way to meeting community members for coffee and "walk and talks."

On the personal level, continuous reflection through this methodological approach prompted the investigators to intentionally shift their behaviors and micro-practices to optimize their own situatedness including well-being and creativity: The PI practiced delegation and "allowed" the IRPP, health fair, and non-profit to form organically, adjusted research focus in order to avoid emotional triggers, committed to eating lunch before 3 pm, crafted a value-laden mission statement for the lab, and carved out time away from email. The GRA re-vamped her morning breathing meditation practice, thwarted work-related rumination by listening to unrelated podcasts during her commute, and stepped away from the computer to hug her husband whenever he arrived home. In line with the Conservation of Resources theory [120, 141] from industrial and organizational psychology, these shifts helped optimize situatedness by conserving and refueling researchers' intrapersonal energy and interpersonal resources to meet the demands of participatory implementation research.

Finally, at the philosophical level, the GRA evolved from focusing on novel methodologies to grappling with deeper ontologies and epistemologies that influence or limit implementation science and participatory research. Paradoxically, the use of a novel methodology (i.e., autoethnography) is what revealed that novel methodologies are not enough: There is a need to examine and align underlying ontological and epistemological foundations of implementation science, including the roles of subjectivity and values within participatory research. PE paleontologists Eldredge and Gould embraced subjectivity within the scientific process when they wrote, "We do not encounter facts as data (literally "given") discovered objectively. All observation is colored by theory and expectation" [118] (p. 85). With a similar nod toward embracing bias, the investigators report the

Table 2 Reporting trustworthiness of qualitative data based on Guba and Lincoln's criteria [142]

\begin{tabular}{|c|c|}
\hline Dimension & Evaluation \\
\hline $\begin{array}{l}\text { Dependability: consistency and accuracy of } \\
\text { findings }\end{array}$ & $\begin{array}{l}\text { Through iterative, ongoing immersion in peer-reviewed literature from a variety of fields, we an- } \\
\text { chored the ethnographic observations in scientific findings. Essentially, we demonstrated that re- } \\
\text { searchers and participatory implementation processes are consistent with concepts from the } \\
\text { social sciences and natural sciences. }\end{array}$ \\
\hline Credibility: truth of the findings & $\begin{array}{l}\text { Our reflexivity statements in the methods section and transparency with which we approached } \\
\text { our own struggles and situatedness indicate that the findings are true to our lived experience } \\
\text { within this IRPP. }\end{array}$ \\
\hline $\begin{array}{l}\text { Confirmability: neutrality and whether findings } \\
\text { are supported by evidence }\end{array}$ & $\begin{array}{l}\text { The findings suggest that we were not neutral and emotionless during the participatory process; } \\
\text { however, we transparently (and vulnerably) reported our own holistic involvement in the process, } \\
\text { triangulating data from cultural artifacts, the GRA field notes, collaborative reconstruction of } \\
\text { events, and ongoing theoretically informed brainstorming. }\end{array}$ \\
\hline Transferability: application in other contexts & $\begin{array}{l}\text { We report our unique lived experience within a unique IRPP and do not expect our exact } \\
\text { thoughts, emotions, and relationships to be replicated in other contexts. However, insight to the } \\
\text { importance of situatedness is transferable to other researchers. Regardless of the scientific } \\
\text { paradigms to which we ascribe or objectivity to which we strive, other researchers can also } \\
\text { leverage the transformative potential of reflection to elevate personal meaning, practical } \\
\text { relevance, and empirical depth. }\end{array}$ \\
\hline
\end{tabular}


trustworthiness of this study in Table 2. In this paper, we have transparently presented our own vulnerabilities and biases as examples of how researcher situatedness may impact participatory approaches to implementation. In addition, we have leveraged interdisciplinarity to interpret these vulnerabilities as untapped opportunities to advance the field of implementation science.

\section{Discussion}

Based on this study, we propose that implementation researcher situatedness influences all aspects of participatory research from planning to dissemination. Situatedness is multifaceted with personal (i.e., the researcher), interpersonal (i.e., the researcher + IRPP), and cultural (i.e., the researcher + implementation science) dimensions that include conscious and unconscious, adaptive and maladaptive drivers. It stands to reason that these drivers influence many manifestations of implementation science, not just participatory research. Therefore, the implications of this work are applicable to all implementation scientists.
This work indicates that autoethnography is a thought-provoking, action-inspiring method to leverage researcher situatedness through critical reflection, capturing empirical aspects of implementation while enhancing the practice of implementation including researchers' own influence on the process. As shown in Figs. 1 and 5, the reflective nature of autoethnography can deepen researchers' understanding of implementation contexts, processes, and outcomes [101, 102] and generate questions within radiating frames of reference. In addition, autoethnography brings interdisciplinary [113] work to life by facilitating the identification and application of theories from other fields, particularly social science [143] where researchers have grappled with realworld messiness for years [144]. Future work in implementation science is needed to distinguish between empirical autoethnography and "mere anecdotes" [97] (p. 198) and to develop strategies for disseminating the breadth and depth of data captured in this time- and energy-intensive method.

Findings in this explicitly reflective work suggest that there are gaps in acknowledging our own

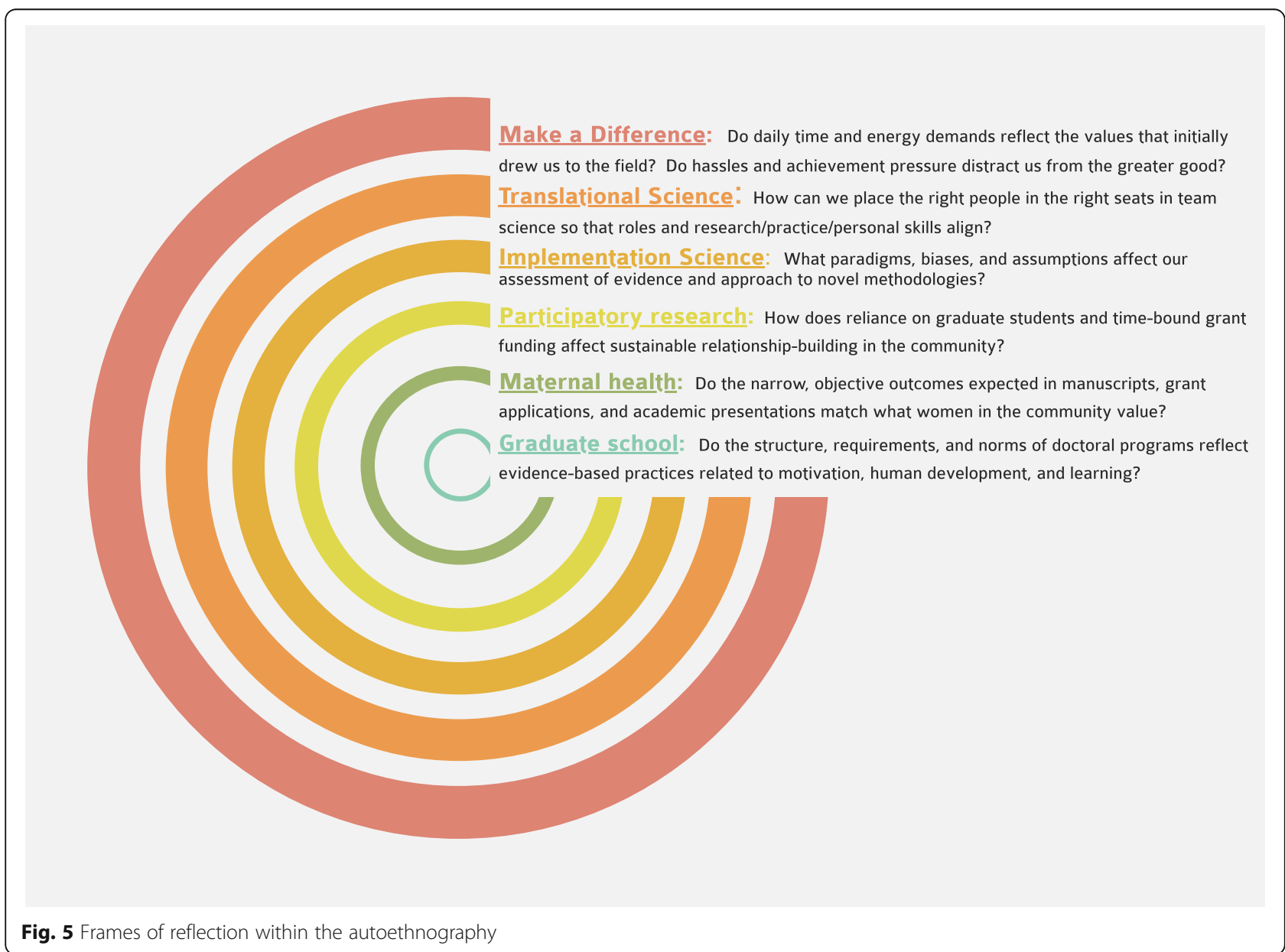


humanness and in investigating "invisible" drivers such as deep ontological and epistemological foundations of implementation science. Without deeper recognition of the ontological and epistemological components of the current implementation paradigm, new methodologies will fall flat; we will not be able to clear the research-real world pipeline that we inadvertently clog through our own attachment to traditional views of what matters and what is. Furthermore, we may exacerbate gaps and blind spots by unintentionally behaving in maladaptive ways that reinforce the culture of workism, demonstrable productivity, and chaos. Within this chaos, we suggest several strategies to optimize situatedness.

First, we suggest incorporating ontological and epistemological inquiry into academic training, team science, and efforts to advance the implementation field. Diving beneath the current focus on matching methods to a research question, researchers should reflect on personal philosophies that underscore or contradict paradigms of what evidence counts [55]. See Table 3 for potential benefits of acknowledging philosophical underpinnings.

Second, we suggest that researchers adopt evidencebased restorative practices that align with one's own values, similar to how elite athletes prioritize recovery in their training regimens $[146,147]$. Potential practices include microbreaks [148, 149], meaningful off-job experiences [150], slow deep breathing [151, 152], and breaks from digital communication [153].

Third, to promote presence, we suggest that researchers focus their senses, intellect, and emotions on the people present in a specific time and place: Acknowledge the potential of "n-of-1" participatory research in which individual, authentic relationships can spiral into unpredicted community benefit in a butterfly effect pattern. Embrace personal presence as a valuable experience in and of

Table 3 Potential benefits of recognizing and clarifying ontological and epistemological paradigms

- Improve communication across the translational spectrum from basic science to clinical science to implementation, dissemination, and policy.

- Leverage the power of values and intrinsic motivation in fostering long-term change, as opposed to relying only on impersonal, measurable mechanisms that do not reflect basic human psychosocial needs such as love, connection, and autonomy [76, 145].

- Engage in rich analysis of novel approaches that may otherwise be quickly rejected because of incongruence with the analyzer or field's deeply held, implicit views as what counts as evidence or knowledge.

- Advance interdisciplinary and transdisciplinary approaches [113] that may be initially discarded because of underlying, mismatched philosophical assumptions between various fields. itself in addition to being a vehicle for relevant empirical productivity.

\section{Conclusion}

Each of these strategies incorporates reflective practice and values as stabilizing mechanisms within the chaos of implementation: Clarity through the chaos of implementation starts with clarity within the researcher-as a situated human being viscerally and cerebrally experiencing life. We may not be able to control dynamic, real-world variables and unpredictable external contexts, but we can choose to maximize our humanness and presence. In leveraging our own situatedness through critical reflection, we can apply implementation-related constructs to ourselves: scale inward, facilitate one's own capacity, protect personal sustainability, seek fidelity to values, and embrace the present context of moment-tomoment time and space. Ultimately, through this critical reflection, implementation scientists may epitomize what Margaret Mead meant by thoughtful citizens changing the world.

\section{Abbreviations}

D\&l: Dissemination and implementation; GRA: Graduate research assistant; GWG: Gestational weight gain; IRPP: Integrated research practice partnership; PE: Punctuated equilibrium; PI: Principal investigator; RCT: Randomized controlled trial; RE-AIM: Reach, effectiveness, adoption, implementation, maintenance; V02 max: Volume of oxygen consumption during maximal exercise

\section{Acknowledgements}

The authors are grateful to the many individuals who fueled the evolution of this project over the last 13 years. This research and community work would not have been possible without their engagement.

\section{Authors' contributions}

AS conducted the autoethnography, wrote the original draft of this paper, and designed the figures and tables. SMH developed the initial concept for this project, was a major contributor to the ethnographic-theoretical dialogue throughout data collection and analysis, and provided vital feedback in the content and design of the manuscript and figures. TA contributed expertise and creativity to incorporating interdisciplinary theories and concepts, as well as interpreting results and crafting the conclusion. All authors read and approved the manuscript.

Funding

In 2019, the first author received a Margaret C. Hepler Summer Research Fellowship to conduct participatory research and autoethnography. This fellowship provides graduate students with funding to continue their research projects over the summer months but does not take an explicit role in collecting, interpreting, or analyzing data. The Virginia Tech Open Access Subvention Fund provided funding to publish this article.

\section{Availability of data and materials}

Publicly sharing all autoethnographic data, including all field notes and cultural artifacts, may compromise personal privacy. Table 1 and the extensive integration of field notes throughout the manuscript provide the minimal data needed to interpret, replicate, and build upon findings reported in this article.

Ethics approval and consent to participate

The Virginia Tech Institutional Review Board approved this project, IRB 18-935. 


\section{Consent for publication}

Not applicable.

\section{Competing interests}

The authors declare that they have no competing interests.

\section{Author details}

'Department of Human Nutrition, Foods, and Exercise, Virginia Tech, 1981 Kraft Drive, Room 1032, Blacksburg, VA 24060, USA. ${ }^{2}$ Department of Agricultural, Leadership, and Community Education, Virginia Tech, 284 Litton-Reaves Hall, Mail Code 0343, Blacksburg, VA 24061, USA.

\section{Received: 11 February 2020 Accepted: 18 May 2020}

Published online: 03 September 2020

\section{References}

1. Israel B, Schulz A, Parker E, Becker A. Community-based participatory research: policy recommendations for promoting a partnership approach in health research. Educ Heal. 2001;14(2):182-97.

2. Bodison SC, Sankaré I, Anaya H, Booker-Vaughns J, Miller A, Williams $P$, et al. Engaging the community in the dissemination, implementation and improvement of health-related research. Clin Transl Sci. 2015:8(6):814-9.

3. Livingood WC, Bilello LA, Choe U, Lukens-Bull K. Enhancing the science of discovery in public health systems and services research through participatory research methods. Popul Health Manag. 2017;21(2):155-62.

4. Brady $\mathrm{V}$, Lalor J. Space for human connection in antenatal education: uncovering women's hopes using Participatory Action Research. Midwifery. 2017;55(January 2016):7-14 Available from: https://doi.org/10.1016/j.midw. 2017.08.006.

5. Keyes D. Earth of Omega: passage to planetization. First Edit. Wellesley: Brandon Publishing Co, Inc.; 1982

6. Van Belle S, Rifkin S, Marchal B. The challenge of complexity in evaluating health policies and programs: the case of women's participatory groups to improve antenatal outcomes. BMC Health Serv Res. 2017;17(1):1-6.

7. Glasgow R. What does it mean to be pragmatic? Pragmatic methods, measures and models to facilitate research translation. Heal Educ Behav. 2013:40(3):257-65.

8. Bauer MS, Damschroder L, Hagedorn H, Smith J, Kilbourne AM. An introduction to implementation science for the non-specialist. BMC Psychol. 2015;3(1):1-12

9. Oliver K, Kothari A, Mays N. The dark side of coproduction: do the costs outweigh the benefits for health research? Heal Res Policy Syst. 2019;17(1): $1-10$.

10. Reed JE, Howe C, Doyle C, Bell D. Simple rules for evidence translation in complex systems: a qualitative study. BMC Med. 2018;16(1):1-20.

11. Howe A, Mathie E, Munday D, Cowe M, Goodman C, Keenan J, et al. Learning to work together - lessons from a reflective analysis of a research project on public involvement. Res Involv Engagem. 2017:3(1):1 Available from: http://researchinvolvement.biomedcentral.com/articles/10.1186/s4 0900-016-0051-x

12. Sawtell M, Sweeney L, Wiggins M, Salisbury C, Eldridge S, Greenberg L, et al. Evaluation of community-level interventions to increase early initiation of antenatal care in pregnancy: protocol for the community REACH study, a cluster randomised controlled trial with integrated process and economic evaluations. Trials. 2018:19(1):1-13.

13. Hamilton CB, Hoens AM, Backman CL, McKinnon AM, McQuitty S, English K, et al. An empirically based conceptual framework for fostering meaningful patient engagement in research. Heal Expect. 2018;21(1):396-406.

14. Harvey G, McCormack B, Kitson A, Lynch E, Titchen A. Designing and implementing two facilitation interventions within the "Facilitating Implementation of Research Evidence (FIRE)" study: A qualitative analysis from an external facilitators' perspective. Implement Sci. 2018;13(1):1-14.

15. Koorts H, Naylor PJ, Laws R, Love P, Maple JL, van Nassau F. What hinders and helps academics to conduct Dissemination and Implementation (D\&l) research in the field of nutrition and physical activity? An international perspective. Int J Behav Nutr Phys Act. 2020;17(1):7.

16. Davidoff F. Understanding contexts: how explanatory theories can help. Implement Sci. 2019;14(1):1-9.

17. Damschroder $L$. Clarity out of chaos: use of theory in implementation research. Psychiatry Res. 2019:283(June 2019).

18. Stoecker R. Are academics irrelevant. Am Behav Sci. 1999;42(5):840-54
19. Guba E, Lincoln Y. Competing paradigms in qualitative research. In: Denzin NK, Lincoln YS, editors. Handbook of qualitative research: SAGE Publications, Inc; 1994. p. 105-17. Available from: http://steinhardtapps.es.its.nyu.edu/ create/courses/3311/reading/10-guba_lincoln_94.pdf.

20. Appleton JV, King L. Journeying from the philosophical contemplation of constructivism to the methodological pragmatics of health services research. J Adv Nurs. 2002;40(6):641-8.

21. Denzin NK. Moments, mixed methods and paradigm dialogs. Qual Inq. 2010:16(6):419-27.

22. Syntetos A, Harwood S. Mixing methodologies and pragmatic commensurability. J Oper Res Soc. 2011;62(4):806-9.

23. Bunger AC, Powell BJ, Robertson HA, MacDowell H, Birken SA, Shea C. Tracking implementation strategies: a description of a practical approach and early findings. Heal Res Policy Syst. 2017;15(1):1-12.

24. Qualitative Research in Implementation Science (QUALRIS). Qualitative methods in implementation science. 2018. Available from: https:// cancercontrol.cancer.gov/IS/docs/NCI-DCCPS-ImplementationScienceWhitePaper.pdf.

25. Tracy S. Qualitative research methods: collecting evidence, crafting analysis, communicating impact. First. Chichester: Blackwell Publishing, Ltd; 2013.

26. Greenhalgh T, Raftery J, Hanney S, Glover M. Research impact: a narrative review. BMC Med. 2016;14(1) Available from: https://doi.org/10.1186/s12916016-0620-8.

27. Hair M, Renaud KV, Ramsay J. The influence of self-esteem and locus of control on perceived email-related stress. Comput Human Behav. 2007;23(6): 2791-803.

28. Kushlev K, Dunn EW. Checking email less frequently reduces stress. Comput Human Behav. 2015:43:220-8 Available from: https://doi.org/10.1016/j.chb. 2014.11.005

29. Mano RS, Mesch GS. E-mail characteristics, work performance and distress. Comput Human Behav. 2010;26(1):61-9 Available from: https://doi.org/10. 1016/j.chb.2009.08.005

30. Leroy S, Schmidt AM. The effect of regulatory focus on attention residue and performance during interruptions. Organ Behav Hum Decis Process. 2016;137:218-35 Available from: https://doi.org/10.1016/j.obhdp.2016.07.006.

31. Leroy S. Why is it so hard to do my work? The challenge of attention residue when switching between work tasks. Organ Behav Hum Decis Process. 2009;109(2):168-81 Available from: https://doi.org/10.1016/j.obhdp. 2009.04.002.

32. Csikszentmihalyi M. Flow: the psychology of optimal experience. New York: Harper Perennial; 1990

33. Ericsson KA. Summing up hours of any type of practice versus identifying optimal practice activities: commentary on Macnamara, Moreau, \& Hambrick (2016). Perspect Psychol Sci. 2016;11(3):351-4.

34. Ericsson KA, Krampe RT, Tesch-Römer $C$. The role of deliberate practice in the acquisition of expert performance. Psychol Rev. 2005;100(3):363-406.

35. Dandar V, Gribsby R, Bunton S. Burnout among U.S. medical school faculty. AAMC Anal Br. 2019;19(1).

36. Messias E, Gathright MM, Freeman ES, Flynn V, Atkinson T, Thrush CR, et al. Differences in burnout prevalence between clinical professionals and biomedical scientists in an academic medical centre: a cross-sectional survey. BMJ Open. 2019;9(2):1-7.

37. Holleman WL, Cofta-woerpel LM, Gritz ER. Stress and morale of academic biomedical scientists. Acad Med. 2015;90(5):562-4.

38. Powell K. Work-life balance: break or burn out. Nature. 2017:545(7654): $375-7$.

39. Kivimäki $M$, Jokela $M$, Nyberg ST, Singh-Manoux A, Fransson El, Alfredsson L, et al. Long working hours and risk of coronary heart disease and stroke: a systematic review and meta-analysis of published and unpublished data for 603838 individuals. Lancet. 2015:386(10005):1739-46.

40. Meijman TF, Mulder G. Psychological aspects of workload. In: Drenth PJ, Theirry H, de WC J, editors. Work Psychology. 2nd ed. East Sussex; 1998. p. 5-28.

41. Debus ME, Sonnentag S, Deutsch W, Nussbeck FW. Making flow happen: the effects of being recovered on work-related flow between and within days. J Appl Psychol. 2014;99(4):713-22.

42. Binnewies C, Sonnentag S, Mojza EJ. Feeling recovered and thinking about the good sides of one's work. J Occup Health Psychol. 2009:14(3):243-56.

43. Zijlstra FRH, Cropley M, Rydstedt LW. From recovery to regulation: an attempt to reconceptualize "recovery from work". Stress Heal. 2014;30(3): 244-52. 
44. Rager KB. Compassion stress and the qualitative researcher. Qual Health Res. 2005;15(3):423-30

45. Gair S. Feeling their stories: contemplating empathy, insider/outsider positionings, and enriching qualitative research. Qual Health Res. 2012;22(1): 134-43

46. Ross LE. An account from the inside: examining the emotional impact of qualitative research through the lens of "insider" research. Qual Psychol. 2017:4(3):326-37.

47. Hubbard G, Backett-milburn K. Working with emotion: issues for the researcher in fieldwork and teamwork. Int J Soc Res Methodol. 2001;4(1): 119-237.

48. Padek M, Mir N, Jacob RR, Chambers DA, Dobbins M, Emmons KM, et al. Training scholars in dissemination and implementation research for cancer prevention and control: a mentored approach. Implement Sci. 2018;13(1):113.

49. Padek M, Colditz G, Dobbins M, Koscielniak N, Proctor EK, Sales AE, et al. Developing educational competencies for dissemination and implementation research training programs: an exploratory analysis using card sorts. Implement Sci. 2015;10(114):1-9.

50. Brosschot JF, Gerin W, Thayer JF. The perseverative cognition hypothesis: a review of worry, prolonged stress-related physiological activation and health. J Psychosom Res. 2006;60(2):113-24.

51. Ottaviani C, Thayer JF, Verkuil B, Lonigro A, Medea B, Couyoumdjian A, et al. Physiological concomitants of perseverative cognition: a systematic review and meta-analysis. Psychol Bull. 2016;142(3):231-59.

52. Cropley M, Zijlstra FRH, Querstret D, Beck S. Is work-related rumination associated with deficits in executive functioning? Front Psychol. 2016;7(SEP): $1-8$.

53. Calderwood C, Bennett AA, Gabriel AS, Trougakos JP, Dahling JJ. Too anxious to help? Off-job affective rumination as a linking mechanism between work anxiety and helping. J Occup Organ Psychol. 2018;91(3):6817.

54. Glasgow R, Estabrooks P. Pragmatic applications of RE-AIM for health care initiatives in community and clinical settings. Prev Chronic Dis. 2018;15(E02).

55. Archibald T. Whose extension counts? A plurality of extensions and their implications for credible evidence debates. J Hum Sci Ext. 2019;7(2):22-35.

56. Creswell JW. Choosing among five approaches. Qualitative Inquiry and Research Design. 2nd ed. Thousand Oaks: SAGE Publications; 2012.

57. Geng EH, Peiris D, Kruk ME. Implementation science: relevance in the real world without sacrificing rigor. PLoS Med. 2017;14(4):1-5.

58. Brownson RC, Colditz GA, Dobbins M, Emmons KM, Kerner JF, Padek M, et al. Concocting that magic elixir: successful grant application writing in dissemination and implementation research. Clin Transl Sci. 2015;8(6):710-6.

59. Star SL, Strauss A. Layers of silence, arenas of voice: the ecology of visible and invisible work. Comput Support Coop Work. 1999;8(1-2):9-30.

60. Daniels AK. Invisible work. Soc Study Soc Probl. 1987;34(5):403-15.

61. Dhara A. Invisible work. Can Fam Physician. 2019;65(61):426-7.

62. Bono JE, Judge TA. Personality and transformational and transactional leadership: a meta-analysis. J Appl Psychol. 2004;89(5):901-10.

63. Hautala TM. The relationship between personality and transformational leadership. J Manag Dev. 2006;25(8):777-94.

64. Barnes CM, Guarana CL, Kong DT. Too tired to inspire or be inspired: sleep deprivation and charismatic leadership. J Appl Psychol. 2016;101(8):1191-9.

65. Schaubroeck J, Lam SSK, Cha SE. Embracing transformational leadership: team values and the impact of leader behavior on team performance. J Appl Psychol. 2007;92(4):1020-30.

66. Bass BM, Avolio BJ, Jung DI, Berson Y. Predicting unit performance by assessing transformational and transactional leadership. J Appl Psychol. 2003;88(2):207-18

67. Smith MJ, Arthur CA, Hardy J, Callow N, Williams D. Transformational leadership and task cohesion in sport: the mediating role of intrateam communication. Psychol Sport Exerc. 2013;14(2):249-57 Available from: https://doi.org/10.1016/j.psychsport.2012.10.002.

68. Syme SL. The science of team science. Assessing the value of transdisciplinary research. Am J Prev Med. 2008;35(2 SUPPL):94-5.

69. Flaxman PE, Ménard J, Bond FW, Kinman G. Academics' experiences of a respite from work: effects of self-critical perfectionism and perseverative cognition on postrespite well-being. J Appl Psychol. 2012;97(4):854-65.

70. Lounsbury JW, Foster N, Patel H, Carmody P, Gibson LW, Stairs DR. An investigation of the personality traits of scientists versus nonscientists and their relationship with career satisfaction. R D Manag. 2012;42(1):47-59.
71. Grosul M, Feist GJ. The creative person in science. Psychol Aesthetics Creat Arts. 2014;8(1):30-43.

72. Baumeister R, Bratslavsky E, Muraven M, Tice D. Ego depletion: is the active self a limited resource? J Pers Soc Psychol. 1998;74(5):1252-65.

73. Baumeister RF, Tice DM, Vohs KD. The strength model of self-regulation: conclusions from the second decade of willpower research. Perspect Psychol Sci. 2018;13(2):141-5.

74. Grimes DR, Bauch CT, loannidis JPA. Modelling science trustworthiness under publish or perish pressure. R Soc Open Sci. 2018;5(171511):1-14 Available from: https://doi.org/10.1098/rsos.171511.

75. Marylène G, Edward LD. Self-determination theory and work motivation. J Organ Behav. 2005;26(4):331-62 Available from: http://usherbrooke.summon. serialssolutions.com/link/0/eLvHCXMwTV3NCsIwDC6i4HmgvfoCHf3feh4 bgiAijs1j0y53f94f41TwFJJLAglf8h2SMLYzIAnzvDPeIVIPyCBtRC8hWQxy_nM4 jFV_dcOhtH9o3hVsgfcN67v20uzF9xmASDQCaxEhEpN7H61MBhNZUFc1 OXFQMQedIHdQO5uTVtMkTCSQLMXhs6syYIBabdmSCPXE2.

76. Deci E, Ryan R. Self-determination theory: a macrotheory of human motivation, development and health. Can Psychol. 2008;49(3):182-5.

77. Lyness JM, Lurie SJ, Ward DS, Mooney CJ, Lambert DR. Engaging students and faculty: implications of self-determination theory for teachers and leaders in academic medicine. BMC Med Educ. 2013;13(1):1

78. Tremblay MA, Blanchard CM, Taylor S, Pelletier LG, Villeneuve M. Work Extrinsic and Intrinsic Motivation scale: its value for organizational psychology research. Can J Behav Sci. 2009;41(4):213-26.

79. Cerasoli CP, Nicklin JM, Ford MT. Intrinsic motivation and extrinsic incentives jointly predict performance: a 40-year meta-analysis. Psychol Bull. 2014; 140(4):980-1008.

80. Elliot AJ, Murayama K. On the measurement of achievement goals: critique, illustration and application. J Educ Psychol. 2008;100(3):613-28.

81. Leggett EL, Dweck CS. A social-cognitive approach to motivation and personality. Psychol Rev. 1988;95(2):256-73 Available from: http://citeseerx. ist.psu.edu/viewdoc/download?doi=10.1.1.583.9142\&rep=rep1\&type=pdf.

82. Utman CH. Performance effects of motivational state: a meta-analysis. Personal Soc Psychol Rev. 1997;1(2):170-82.

83. Shanafelt T, West C, Sloan J, Novotny P, Poland G, Menaker R, et al. Career fit and burnout among academic faculty. Arch Intern Med. 2009:169(10): 990-5 Available from: http://www.embase.com/search/results?subaction= viewrecord\&from=export\&id=L354671349\%0A, http://archinte.ama-assn.org/ cgi/reprint/169/10/990\%0A, https://doi.org/10.1001/archinternmed.2009.70.

84. Searle B, Auton J. The merits of measuring challenge and hindrance appraisal. Anxiety Stress Coping. 2015;28:121-43.

85. Boswell WR, Olson-Buchanan JB, LePine MA. Relations between stress and work outcomes: the role of the felt challenge, job control and psychological strain. J Vocat Behav. 2004;64(1):165-81.

86. French KA, Allen TD, Henderson TG. Challenge and hindrance stressors and metabolic risk factors. J Occup Health Psychol. 2019;24(3):307-21.

87. Cavanaugh MA, Boswell WR, Boudreau JW. "Challenge" and "Hindrance" related stress among U.S. managers. Cornell Univ Digit Commons. 1998; (May 2014):27.

88. Rosen C. The myth of multitasking. New Atl. 2008;20(Spring):105-10.

89. González VM, Mark G. "Constant, constant, multi-tasking craziness": managing multiple working spheres. Most. 2004;6(1):113-20 Available from: http://portal.acm.org/citation.cfm?id=985707.

90. Conte KP, Shahid A, Grøn S, Loblay V, Green A, Innes-hughes C, et al. Capturing implementation knowledge: applying focused ethnography to study how implementers generate and manage knowledge in the scale-up of obesity prevention programs. Implement Sci. 2019;14(91):1-14.

91. Neumann C, Neumann I. Uses of the self: two ways of thinking about scholarly situatedness and method. Milen J Int Stud. 2015;43(3):798-819.

92. Vannini P. Situatedness. In: Given LM, editor. The SAGE encyclopedia of qualitative research methods. Thousand Oaks: SAGE Publications, Inc.; 2012. p. 815-6. Available from: https://methods.sagepub.com/base/download/ ReferenceEntry/sage-encyc-qualitative-research-methods/n424.xml.

93. Green CA, Duan N, Gibbons RD, Hoagwood KE, Palinkas LA, Albert G, et al. Approaches to mixed methods dissemination and implementation research: methods, strengths, caveats, and opportunities. Adm Policy Ment Health. 2016:42(5):508-23.

94. Creswell J, Poth C. In: Salmon H, editor. Qualitative inquiry \& research design. 4th ed. Thousand Oaks: SAGE Publications; 2018.

95. Rogozińska E, Marlin N, Jackson L, Rayanagoudar G, Ruifrok AE, Dodds J, et al. Effects of antenatal diet and physical activity on maternal and fetal 
outcomes: individual patient data meta-analysis and health economic evaluation. Health Technol Assess (Rockv). 2017;21(41).

96. Fook J. Developing Critical Reflection As a Research Method. In: Higgs J, Titchen A, Horsfall D, Bridges D, editors. Creative spaces for qualitative researching: living research. Rotterdam: Sense Publishers; 2011. p. 55-64.

97. Brookfield S. Critically reflective practice. J Contin Educ Health Prof. 1998; 18(1st):197-205.

98. Mortari L. Reflectivity in research practice. Int J Qual Methods. 2015;14(5): 160940691561804

99. Lincoln YS, Guba EG. Naturalistic inquiry. Newbury Park: SAGE Publications; 1985.

100. Van Horn L, Beto J. In: Van Horn L, Beto J, editors. Research successful approaches in nutrition and dietetics. 4th ed. Chicago: Academy of Nutrition and Dietetics; 2019.

101. Gerke D, Lewis E, Prusaczyk B, Hanley C, Baumann A, Proctor E. Implementation Outcomes. St. Louis: Washington University; 2017. Eight toolkits related to Dissemination and Implementation. Available from https://sites.wustl.edu/wudandi.

102. Proctor E, Silmere H, Raghavan R, Hovmand P, Aarons G, Bunger A, et al. Outcomes for implementation research: conceptual distinctions, measurement challenges and research agenda. Adm Policy Ment Heal Ment Heal Serv Res. 2011;38(2):65-76.

103. Estabrooks PA, Harden SM, Almeida FA, Hill JL, Johnson SB, Porter GC, et al. Using integrated research-practice partnerships to move evidence-based principles into practice. Exerc Sport Sci Rev. 2019;47(3):176-87.

104. Harden SM, Johnson SB, Almeida FA, Estabrooks PA. Improving physical activity program adoption using integrated research-practice partnerships: an effectiveness-implementation trial. Transl Behav Med. 2017;7(1):28-38.

105. Johnson SB, Harden SM, Estabrooks PA. Uptake of evidence-based physical activity programs: comparing perceptions of adopters and nonadopters. Transl Behav Med. 2016;6(4):629-37 Available from: https://doi.org/10.1007/ s13142-015-0371-7.

106. Wilson ML, Strayer TE, Davis R, Harden SM. Informed adaptations of a strength-training program through a research-practice partnership. Front Public Heal. 2018;6(March):1-9 Available from: http://journal.frontiersin.org/ article/10.3389/fpubh.2018.00058/full.

107. Harden S, Beauchamp M, Pitts B, Nault E, Davy B, You W, et al. Group-based lifestyle sessions for gestational weight gain management: a mixed method approach. Am J Health Behav. 2014;38(4):560-9 Available from: http:// ovidsp.ovid.com/ovidweb.cgi?T=JS\&PAGE=reference $\& D=$ emed16\&NEWS $=$ $N \& A N=613394541$

108. Gerrard N. Some painful experiences of a white feminist therapist doing research with women of color. In: Adleman J, editor. Racism in the lives of women. Binghamton: Harrington Park Press; 1995. p. 55-64.

109. Breen $L$. The researcher 'in the middle': negotiating the insider/outsider dichotomy. Aust Community Psychologist. 2007;19(1):163-74

110. Pink S, Morgan J. Short-term ethnography: intense routes to knowing. Symb Interact. 2013;36(3):351-61.

111. Emerson MR, Fretz RI, Shaw LL. Fieldnotes in ethnographic research. Writ Ethnogr Fieldnotes. 1995:1-32.

112. Nilsen P. Making sense of implementation theories, models and frameworks. Implement Sci. 2015;10(1):1-13.

113. Choi B, Pak A. Multidisciplinarity, interdisciplinarity and transdisciplinarity in health research, services, education and policy: 1. Definitions, objectives and evidence of effectiveness. Clin Investig Med. 2006;29(6):351-64.

114. Blythe $S$, Wilkes $L$, Jackson $D$, Halcomb $E$. The challenges of being an insider in storytelling research. Nurse Res. 2013;21(1):8-12.

115. Aarons GA, Sklar M, Mustanski B, Benbow N, Brown CH. "Scaling-out" evidence-based interventions to new populations or new health care delivery systems. Implement Sci. 2017;12(1):1-13.

116. Gleick J. Making a new science: Chaos. New York: Penguin Books; 1987.

117. Lorenz E. Predictability: does the flap of a butterfly's wings in Brazil set off a tornado in Texas?. 1972. Available from: http://www.ias.ac.in/article/fulltext/ reso/020/03/0260-02

118. Eldredge N, Gould S. Punctuated equilibria: an alternative to phyletic gradualism. In: Schopf T, editor. Models in paleobiology. San Francisco: Freeman Cooper \& Co; 1972. p. 82-115.

119. Spence GB, Stout-Rostron S, Van Reenen M, Glashoff B. Exploring the delayed effects of leadership coaching: a pilot study. Coaching. 2019;12(2): $125-46$.
120. Picciotto R, Donald T. Campbell's evolutionary perspective and its implications for evaluation. J Multidiscip Educ. 2019;15(33):1-15.

121. Dewe P, O'Driscoll M, Cooper C. Theories of Psychological Stress at Work. In: Gatchel R, Schultz I, editors. Handbook of occupational health and wellness. New York: Spring Science + Business Media; 2012

122. Flett $G$, Hewitt P. Perfectionism and maladjustments: an overview of theoretical, definitional, and treatment issues. In: Flett $G$, Hewitt P, editors. Perfectionism: Theory, research, and treatment. Washington, DC: American Psychological Association; 2002. p. 5-32.

123. Horne R, Petrie K, Wessley S. H-index pathology. BMJ. 2009;339(b5356):1447-8.

124. Elliot AJ, McGregor HA. A $2 \times 2$ achievement goal framework. J Pers Soc Psychol. 2001;80(3):501-19.

125. Grant A, Franklin J, Langford P. The self-reflection and insight scale: a new measure of private self-consciousness. Soc Behav Pers. 2002;30(8):821-36.

126. Harrington R, Loffredo DA. Insight, rumination, and self-reflection as predictors of well-being. J Psychol Interdiscip Appl. 2011;145(1):39-57.

127. Thompson D. Workism is making Americans miserable: The Atlantic; 2019 Feb. Available from: https://www.theatlantic.com/ideas/archive/2019/02/ religion-workism-making-americans-miserable/583441/.

128. Gidden A. The constitution of society: outline of the theory of structuration. Berkeley: University of California Press; 1984

129. Zuidgeest M, Goetz I, Groenwold R, Irving E, van Thiel G, Grobbe D. Series: pragmatic trials and real world evidence: Paper 1. Introduction. J Clin Epidemiol. 2017;88:7-13.

130. Thorpe KE, Zwarenstein M, Oxman AD, Treweek S, Furberg CD, Altman DG, et al. A pragmatic-explanatory continuum indicator summary (PRECIS): a tool to help trial designers. J Clin Epidemiol. 2009;62(5):464-75 Available from: https://doi.org/10.1016/j.jclinepi.2008.12.011.

131. Institute of Development Studies. Participatory methods: reflective practice. [cited 2020 Jan 22]. Available from: www.participatorymethods.org/ methods/reflective-practice.

132. Biesta G. Why "What Works" still won't work: from evidence-based education to value-based education. Stud Philos Educ. 2010;29:491-503.

133. Biesta G. On the two cultures of educational research, and how we might move ahead: reconsidering the ontology, axiology and praxeology of education. Eur Educ Res J. 2015;14(1):11-22.

134. Scotland J. Exploring the philosophical underpinnings of research: relating ontology and epistemology to the methodology and methods of the scientific, interpretive and critical research paradigms. Engl Lang Teach. 2012;5(9):9-16.

135. Fulford K. Values-based practice: a new partner to evidence-based practice and a first for psychiatry. Mens Sana Monogr. 2008;6(1):10-21.

136. Bae J-M. Value-based medicine: concepts and application. Epidemiol Health. 2015;37:e2015014.

137. Tabak RG, Khoong EC, Chambers D, Brownson RC. Models in dissemination and implementation research: useful tools in public health services and systems research. Am J Prev Med. 2012:43(3):337-50.

138. Walton G. Beyond winning. Champaign: Leisure Press; 1992.

139. Wooden J, Jamison S. Wooden on leadership. New York: McGraw-Hill; 2005.

140. Glasgow RE, Harden SM, Gaglio B, Rabin B, Smith ML, Porter GC, et al. REAIM planning and evaluation framework: adapting to new science and practice with a 20-year review. Front Public Heal. 2019;7(March).

141. Hobfall S. Conservation of resources. Am Psychol. 1989:44(3):513-24.

142. Lincoln YS, Guba EG. Establishing trustworthiness. Naturalistic Inquiry. Newbury Park: Sage Publications; 1985. p. 289-331.

143. Van Belle $S$, Van De Pas R, Marchal B. Towards an agenda for implementation science in global health: there is nothing more practical than good (social science) theories. BMJ Glob Heal. 2017;2(2):2016-8.

144. Law J. After method: mess in social science research. Abingdon: Routledge; 2004

145. Maslow A. A theory of human motivation. Psychol Rev. 1943;50:370-96.

146. Mujika I. Tapering and peaking for optimal performance. Champaign: Human Kinetics; 2009

147. Bales M, Swank A. In: Bayles MP, Swank AM, editors. ACSM's exercise testing and prescription. Philadelphia: Wolters Kluwer; 2018.

148. Kim S, Park YA, Niu Q. Micro-break activities at work to recover from daily work demands. J Organ Behav. 2017;38(1):28-44.

149. Lee KE, Williams KJH, Sargent LD, Williams NSG, Johnson KA. 40-second green roof views sustain attention: the role of micro-breaks in attention restoration. J Environ Psychol. 2015:42:182-9 Available from: https://doi.org/ 10.1016/j.jenvp.2015.04.003 
150. Ouyang K, Cheng BH, Lam W, Parker SK. Enjoy your evening, be proactive tomorrow: how off-job experiences shape daily proactivity. J Appl Psychol. 2019.

151. Zaccaro A, Piarulli A, Laurino M, Garbella E, Menicucci D, Neri B, et al. How breath-control can change your life: a systematic review on psychophysiological correlates of slow breathing. Front Hum Neurosci. 2018;

12(September):1-16 Available from: https://www.frontiersin.org/article/10.33 89/fnhum.2018.00353/full.

152. Gerritsen RJS, Band GPH. Breath of life: the respiratory vagal stimulation model of contemplative activity. Front Hum Neurosci. 2018;12(October):397 Available from: https://www.frontiersin.org/article/10.3389/fnhum.2018.003 97/full.

153. Perlow L. Sleeping with your smartphone. Boston: Harvard Business Review Press; 2012

\section{Publisher's Note}

Springer Nature remains neutral with regard to jurisdictional claims in published maps and institutional affiliations.

Ready to submit your research? Choose BMC and benefit from:

- fast, convenient online submission

- thorough peer review by experienced researchers in your field

- rapid publication on acceptance

- support for research data, including large and complex data types

- gold Open Access which fosters wider collaboration and increased citations

- maximum visibility for your research: over $100 \mathrm{M}$ website views per year

At BMC, research is always in progress.

Learn more biomedcentral.com/submissions 